\title{
ODSTUPANJA GOVORNIKA HRVATSKOGA KAO NASLJEDNOG JEZIKA U FRANCUSKOM JEZIČNOM OKRUŽJU
}

APSTRAKT: Sustavnijeg ispitivanja poteškoća koje se javljaju kod nasljednih govornika hrvatskoga $\mathrm{u}$ francuskom jezičnom okružju do sada nije bilo. U ovom će se radu stoga identificirati, zabilježiti, raščlaniti i opisati najčešće poteškoće koje se pojavljuju u korpusu pisanih radova iz hrvatskog jezika s državne mature u Republici Francuskoj, pri čemu se koristi pojam odstupanja. Raščlamba odstupanja u ovom slučaju potvrđuje polazišnu pretpostavku o prisutnosti neizvornih, razvojnih i prijelaznih odstupanja, ali i onih izvornih. Stoga bi rezultati ove raščlambe mogli doprinijeti postavljanju smjernica za nastavu hrvatskog jezika u Francuskoj kako u hrvatskim dopunskim školama tako i unutar programa poučavanja jezika i kulture podrijetla («enseignement de langue et de culture d'origine », ELCO), odnosno na sveučilišnoj razini.

Ključne riječi: hrvatski jezik, francusko jezično okružje, izvorna odstupanja, neizvorna odstupanja.

\section{CROATIAN HERITAGE SPEAKERS' ERRORS IN FRENCH LANGUAGE ENVIRONMENT}

\begin{abstract}
A more systematic examination of the difficulties encountered by heritage speakers of the Croatian language in French language environment has not existed so far. This paper will therefore identify, record, analyze and describe, using the concept of error, the most common difficulties that occur in a corpus of written exams on the Croatian language at the baccalaureate, the State High School Exit Exam in the Republic of France. The analysis of errors in this case consequently confirms the initial hypothesis of the presence of non-native, developmental and transfer errors, but also of the native ones. The results of this analysis could contribute to the establishment of guidelines for the teaching of the Croatian language in France, both in the Croatian supplementary schools and in the ELCO program (" enseignement de langue et de culture d'origine "), as well at the university level.
\end{abstract}

Key words: Croatian language, French language environment, native errors, non-native errors.

\section{UVODNA RAZMATRANJA}

U suvremenoj teorijskoj literaturi s područja poučavanja materinskih i inih jezika pojam pogrješke ili greške zamjenjuje se pojmom odstupanja. Pojmovi pogrješke, propusta i odstupanja zapravo se odnose na tri različite pojave (Jelaska 
2005): pogrješka je oblik koji bi učenik već trebao naučiti, a nije, propust je povremena poteškoća, dok se odstupanje smatra obilježjem međujezika osobe koja jezik uči. Odstupanja se općenito određuju kao otkloni od jezične norme koji se javljaju pri učenju drugoga, odnosno inoga jezika, ali i pri učenju standardnoga materinskoga jezika budući da tijekom učenja, uslijed jezičnog razvoja, dolazi do supostojanja usporednih jezičnih kodova (Macan, Kolaković 2008). Nadalje, postoje različite podjele odstupanja (Gulešić-Machata, Udier 2008). Tako se mogu razlikovati izvorna i neizvorna odstupanja. Izvorna su ona odstupanja koja se pojavljuju kod izvornih govornika kao otkloni od jezične norme, kao i odstupanja u standardnom jeziku koja supostoje s normativnim oblicima. Izvorna odstupanja javljaju se i kod učenika koji ini jezik uče u zemlji u kojoj se taj jezik izvorno govori. Ona se tada uglavnom javljaju uslijed usvajanja nestandardnih idioma, a ne učenjem jezika u okviru obrazovnih ustanova. Neizvorna su odstupanja pak svojstvena međujeziku neizvornih govornika. Mogu biti razvojna i ne ovisiti o njihovu prvom jeziku, te prijenosna, kada su posljedica prijenosa jezičnih elemenata iz dominantnog jezičnog sustava u sustav drugoga jezika (Macan, Kolaković 2008: 35). Naime, kontrastivna lingvistika smatra kako u načelu prvi jezik (J1) utječe na usvajanje inog jezika bilo pozitivno, te se tada govori o pozitivnom transferu, bilo negativno, kada je riječ o interferenciji ili negativnom transferu (Fredet 2006: 107, Sörés 2008: 18). Prijenosna odstupanja mogu se stoga promatrati kao podvrsta neizvornih odstupanja koja nastaju pod utjecajem prvog jezika učenika, no mogu se promatrati i unutar neizvornih odstupanja općenito. I izvorna i neizvorna odstupanja moguće je nadalje razlikovati po razinama - fonološkoj, morfološkoj, sintaktičkoj, semantičkoj, pragmatičkoj i kulturološkoj, a često se istovremeno javljaju na više razina, odnosno višestruka su, uslijed čega jezična poruka postaje teže razumljiva ili čak nerazumljiva.

Dosad provedna istraživanja odstupanja u hrvatskom jeziku mahom su se odnosila na proučavanje međujezika izvornih govornika njemačkog, engleskog, slovačkog, slovenskog, te talijanskog jezika, a istraživanja su provodili J. Novak, N. Globan, Z. Jelaska, V. Požgaj Hadži, M. Gulešić, G. Hržica, M. Alujević Jukić i T. Brešan (Alujević Jukić, Brešan 2010: 242). Cilj je ovoga rada pak analizirati odstupanja govornika hrvatskog jezika u francuskom jezičnom okružju, pri čemu su kao korpus poslužili pisani radovi nastali u okviru provedbe ispita iz hrvatskog jezika na državnoj maturi u Republici Francuskoj 2016. i 2017. godine. Riječ je dakle o ispitanicima koji uz hrvatski vladaju i francuskim jezikom.

\subsection{O provedbi državne mature u Republici Francuskoj}

Tradicija provedbe državne mature u Republici Francuskoj vrlo je duga, naime, matura je u ovoj zemlji prvi puta provedena 1808. godine. U Francuskoj postoje tri vrste mature: baccalauréat général, koja je primjerice slična gimnazijskoj maturi u Republici Hrvatskoj, a polaže je najveći broj maturanata, njih više od 50 posto, te dvije različite strukovne mature: baccalauréat technologique (s 
oko 20 posto pristupnika) i baccalauréat professionnel (s oko 28 posto pristupnika). ${ }^{1}$ Polaganje opće mature u pravilu omogućuje izravni upis na fakultete. Baccalauréat technologique i baccalauréat professionnel ne dozvoljavaju pak upis na fakultete, ali omogućuju upis na specijalističke dvogodišnje studije. Nadalje, u Francuskoj uz opće gimnazije, lycée général, postoje još dva tipa gimnazija, lycée technologique te lycée professionnel koje su usporedive sa srednjim strukovnim školama u Republici Hrvatskoj. U općim gimnazijama nakon prvog razreda učenici biraju jedan od ponuđenih smjerova: Littéraire, Scientifique ili Sciences économiques et sociales. U okviru lycée technologique također postoji više smjerova, poput Sciences et technologies de l'industrie et du développement durable, Sciences et technologies du design et des arts appliqués, Sciences et technologies de laboratoire itd. I tzv. lycée professionnel nudi različite smjerove, kao mécanique, bâtiment, secrétariat, comptabilité. Naglasimo još da se na maturi polažu ispiti iz svih školskih predmeta. Matura stoga obuhvaća 12 do 13 predmeta, dakle vrlo je opširna.

U okviru mature učenici obvezno polažu ispit iz inog jezika, tzv. «langue vivante (étrangère ou régionale)». Nadalje, učenici jezičnom ispitu osim na razini LV1 (prvi strani jezik, J2), mogu pristupiti i na razini LV2 (drugi strani jezik, J3), te LV3 (treći strani jezik, J4), a sami procjenjuju na kojoj će razini polagati pojedini jezik. Ispit iz prvog inog jezika obvezatan je za sve maturante, dok se drugi ili treći ini jezik polažu obvezatno ili izborno, ovisno o gimnazijskom smjeru. Početkom svake kalendarske godine na službenim mrežnim stranicama francuskog Ministarstva obrazovanja i u njegovu službenom glasilu ${ }^{2}$ objavljuje se lista jezika kojima je, uz općeprisutni engleski, njemački, španjolski i talijanski, na maturi moguće pristupiti, a ona obično broji gotovo 50 jezika. Svi jezici sa službene liste nisu pak svrstani u kategoriju obvezatnih, nego se neki mogu odabrati isključivo kao izborni, a među njima je i hrvatski koji se na maturi može polagati od 2004. godine. Međutim, hrvatski je ipak moguće polagati i kao prvi ili drugi jezik. Naime, pristupnici stranog porijekla koji u Francuskoj borave kraće od dvije godine, te se nisu u potpunosti školovali u ovoj državi, imaju pravo umjesto prvog ili drugog obvezatnog inog jezika odabrati svoj materinski jezik. U tzv. lycée professionnel hrvatski se pak na maturi polaže usmeno, kao izborni predmet.

\section{OPIS ISPITANIKA, GRAĐE I ISTRAŽIVANJA}

Hrvatski jezik na državnoj maturi u Francuskoj svrstan je u skupinu malih, odnosno tzv. rijetkih jezika (« langues rares »). Ispitni materijal za strane jezike na

\footnotetext{
1 Riječ je podacima za školsku godinu 2015./16. preuzetima s mrežne stranice https://publication.enseignementsup-recherche.gouv.fr/eesr/10/EESR10_ES_07le_baccalaureat_et_les_bacheliers.php

${ }^{2}$ Le bulletin officiel de l'Education nationale, http://www.education.gouv.fr/pid285/ bulletin_officiel.html?cid_bo=109192
} 
maturi, pa tako i hrvatski, općenito se sastoji od teksta duljine 20-30 redaka, izvorno napisanog na jeziku koji se testira. Tekst može biti ulomak iz nekog književnog djela ili pak novinski članak. Slijede pitanja za provjeru razumijevanja pročitanog, a odnose se na temu teksta, najvažnije informacije u tekstu, postupke likova i/ili argumente i zaključke iznesene u tekstu, te, za izborni predmet, prijevod jednog dijela teksta (od 5 do 8 redaka). Za pristupnike koji strani jezik polažu kao LVI pak nema prijevoda. Drugi dio ispita odnosi se na pismeno izražavanje, te pristupnici pišu sastavak na jednu od dvije ponuđene teme koje su vezane uz glavni tekst, osim pristupnika za $L V 2$, koji pišu sastavak na obje teme. Ovi se pisani radovi ocjenjuju ukupnom ocjenom od 0 do 20, kao zbroj ocjene dobivene za razumijevanje pročitanog teksta (maksimalno 10/10) i pismenog izražavanja (također maksimalno 10/10).

U školskoj godini 2015./2016. pismenom ispitu iz hrvatskog jezika na općoj i tehnološkoj maturi pristupilo je ukupno 72 učenika. Ispitni radovi 2016. godine pristigli su iz sljedećih akademija, odnosno obrazovnih-ispitnih područja u Francuskoj: Pariz-Versailles-Créteil (17 radova), Dijon (3), Grenoble (5), Strasbourg (7), Nica (7), Toulouse (1), Nancy-Metz (5), Reims (2), Amiens (2), Montpellier (2), Lille (2), Aix-en-Provence (1), dok za određeni broj radova, njih 18, nije navedeno odakle dolaze. Od sedamdeset dvoje pristupnika pismenom ispitu, za sedamdesetero njih riječ je bila o fakultativnom ispitu, dok su ga dvoje polagali kao $L V 1$. Nije bilo pristupnika za $L V 2$. Srednja ocjena za pristupnike ispitu iz prvog stranog jezika bila je 19,5/20, a za preostale pristupnike 12,73/20. Školske godine 2016./2017. na općoj i tehnološkoj maturi pismenom ispitu iz hrvatskog jezika pristupilo je ukupno 86 učenika, a njihovi su radovi pristigli iz sljedećih akademija: Pariz-Versailles-Créteil (22 rada), Dijon (2), Grenoble (4), Strasbourg (12), Nica (3), Nancy-Metz (10), Reims (1), Amiens (1), Montpellier (2), AixMarseille (3), Lyon (5), Orélans-Tours (3), Réunion (1), Clermont-Ferrand (5), Bordeaux (3), Nantes (1), Besançon (8). Za sve je pristupnike riječ bila o fakultativnom ispitu. Postigli su prosječnu ocjenu 13,60/20.

Građa za ovo istraživanje odstupanja je dakle sedamdeset radova s opće i tehnološke mature iz 2016. godine, te osamdeset šest radova iz 2017. u kojima su pristupnici izabrali hrvatski kao svoj izborni jezik. Dva rada iz 2016. u kojima su pristupnici polagali hrvatski kao LV1 nisu uzeta u obzir budući da ti pristupnici očito nisu kontinuirano boravili niti se školovali u Francuskoj. Za preostale ispitanike, iako su anonimni, nedvojbeno je da su u francuskom srednjoškolskom sustavu proveli više od dvije godine, te da im je hrvatski nasljedni jezik. Naime, prema Jelaski (2014: 83)

Nasljedni je jezik jedna od podskupina inih jezika. Nasljedni jezik njegovi govornici usvajaju u obitelji ili užoj zajednici koji se nalazi u okružju glavnoga jezika širega društva. Iz ove odrednice proizlazi nekoliko obilježja prototipnoga nasljednoga govornika: on svoj nasljedni jezik nužno usvaja, njime bar do neke mjere vlada pa je dvojezičan (bar u širemu smislu te riječi) jer uz glavni okolinski jezik bar razumije nasljedni jezik ako ga i ne govori. 
Nadalje, po Jelaski (2014: 84), nasljedni govornici po mnogim obilježjima nisu jedinstvena skupina, nego uključuju širok raspon od onih koji samo donekle razumiju svoj nasljedni jezik do onih koji su gotovo uravnoteženo dvojezični u nasljednome i glavnome jeziku, što zapravo i potvrđuju rezultati mature iz hrvatskog jezika svojim rasponom ocjena od 0/20 do 20/20. Unatoč takvoj heterogenosti ispitanika, riječ je o jedinstvenom korpusu radova učenika koji su više godina školovani na francuskom jeziku, te su odlučili polagati hrvatski jezik na maturi, stoga ovo istraživanje zapravo omogućuje dobar uvid u poteškoće govornika hrvatskog jezika u Francuskoj.

Kako sustavnijeg ispitivanja poteškoća koje se javljaju kod govornika hrvatskog jezika u francuskom jezičnom okružju do sada nije bilo, u ovom će se radu identificirati, zabilježiti i opisati i raščlaniti najčešće pravopisne, gramatičke i leksičke poteškoće koje se pojavljuju u navedenom korpusu pisanih učeničkih radova s mature, pri čemu se koristi, kako je već naglašeno, pojam odstupanja. Polazišna je pretpostavka da se u radovima uz neizvorna, razvojna i prijelazna odstupanja, javljaju i ona izvorna. Svim će se odstupanjima pristupiti na nekoliko razina, ponajprije pravopisnoj i fonološkoj, te potom i gramatičkoj i leksičkoj, naravno, uz napomenu da ponekad odstupanja uključuju više od jedne razine, pa otuda poteškoća $u$ točnijem određivanju pojedine vrste odstupanja, te da ih je moguće i drugačije klasificirati, odnosno da je njima moguće potkrijepiti i neki drugi tip odstupanja.

\section{NEIZVORNA ODSTUPANJA U PISANIM RADOVIMA IZ HRVATSKOG JEZIKA NA DRŽAVNOJ MATURI U REPUBLICI FRANCUSKOJ}

\subsection{Razvojna odstupanja}

A) Kako su analizirani pisani radovi, odstupanja na pravopisnoj i fonološkoj razini mogla bi se smatrati isključivo pravopisnim, no može se pretpostaviti da se iza njih kriju ona fonološka, odnosno da su pristupnici bili nesigurni ili da ne poznaju točan izgovor pojedinih riječi. Naime, zamjetno je korištenje pogrešnih grafema za bilježenje pojedinih fonema. Nadalje, kao podvrstu ovog odstupanja navedimo poteškoće u bilježenju nepčanika u vidu učestalog izostavljanja dijakritičkih znakova, kao i korištenja dijakritičkih znakova koji se u standardnom hrvatskom jeziku ne koriste.

a) Bilježenje pogrešnog fonema

usfoimo (umj. usvojimo)

odvoreni (umj. otvoreni)

negome (umj. nekome)

takoče (umj. također)

b) Bilježenje nepčanika

i. Neodgovarajući grafem 
žnaci (umj. znači)

voži (umj. vozi)

ii. Izostavljanje dijakritičkih znakova

potrosnjom (umj. potrošnjom)

Ja se ne slazem. (umj. ne slažem)

iii. Uporaba nepostojećih dijakritičkih znakova

vožacia (umj. vozača)

najvise (umj. najviše)

măcka, păs (umj. mačka, pas)

B) Na morfološkoj razini česta razvojna odstupanja u sklonidbi imenica, pridjeva i zamjenica, dugoj i kratkoj množini, odstupanja u broju imenica, te glagolskim nastavcima i glagolskom vidu.

a) Sklonidba imenica, pridjeva i zamjenica

Zbog videoigru se može ... nervirat. (umj. videoigre)

Sa prijateljima ili familiju... (umj. familijom, obitelji)

Ljudi nemaju koriste od toga. (umj. koristi)

za osvijetljenje društvene mehanizme (umj. društvenih mehanizama)

... a ne od nekog drugo (umj. drugog)

video igrač tko dobie (umj. koji)

Ljudi brinu za njima. (umj. za njih)

b) Duga množina

Postoji više tipa igrica. (umj. tipova)

c) Broj

Sa igrama trebamo se smijati i biti sretan sa prijateljima ili familijom. (umj. biti sretni)

Videoigre sa prijateljima ili familiju može smiješno biti. (umj. Videoigre s prijateljima ili obitelji mogu biti smiješne./Igrati videoigre s prijateljima ili obitelji može biti smiješno.)

d) Konjugacije glagola

Kad vidu (umj. kad vide)

Da se zabavam (umj. da se zabavim)

Neki misla (umj. neki misle)

Poticuju (umj. potiču)

Pomagaju (umj. pomažu)

Oni brine za hranu. (umj. brinu)

Svi volu medvjede. (umj. vole) 
e) Glagolski vid

Predlaže vozaču da osvaja nagradu. (umj. osvoji)

Nadam se da ču imati jednu novu priliku da vam ponovo dolazim. (umj. dođem)

C) Na sintaktičkoj razini uočena su brojna odstupanja u redoslijedu riječi u rečenici i glagolskoj rekciji, te izboru neadekvatnog veznika kao u sljedećim primjerima:

a) Odstupanja u redoslijedu riječi u rečenici

Bi malu potrošnju imao. ( umj. Imao bi malu potrošnju.)

Ali videoigre mogu isto pozitivne stvari biti. (umj. Ali videoigre isto mogu biti pozitivna stvar.)

Zato mogao bi i dresirani majmun igrati te igre. (umj. Zato bi i dresirani majmun mogao igrati te igre.)

b) Glagolska rekcija

igrati ove videoigrici (umj. videoigrice)

zna ... riječiti problemi (umj. riješiti probleme)

Mogu nam provesti oko medvjeđih nastambi. (umj. nas)

c) Neodgovarajući veznik

... možemo ići na odmor bez kućnog ljubimca iako odemo naći nekog ko zna da održava kućnog ljubimca. (umj. a ako, te ako)

D) Odstupanja na leksičkoj razini ponajprije se očituju neodgovarajućim izborom riječi.

\section{a) Odabir riječi}

Misle ... da sve može buditi igra. ( umj. biti igra)

... ludifikacija djeluje na učenike, a ne na uzroke ... (umj. učinke)

Imati kućnog ljubimca ima svoje pozitivne i svoje negativne strane. ... Po mom mišljenju kučni ljubimci imaju više pozitivan utisak nego negativan. ... Sa nama su u dobrom i zlu. (umj. učinak, svojstvo)

Uporan dan (umj. naporan)

Možemo se također igrati s mačkom, mazati se s njima. (umj. maziti)

U Kutarevu, lokalni stanovnici se podnose na vrlo poseban način prema medvjedima. (umj. odnose)

Prvi cilj je zabrinjavanje medvjedića. (umj. zbrinjavanje medvjedića)

b) Nepotpuno poznavanje kolokacija

Njihovo prirodne stanije (umj. prirodno stanje)

Išla sam ... da se okupiram za stare osobe $u$ starom domu... (umj. staračkom domu, odnosno domu za starije ili domu umirovljenika)

U pravu, oni su tu kao vodiči, mogu vam pokasati medvjede... (umj. u pravilu) 


\subsection{Prijenosna odstupanja}

A) Pravopisna i fonološka razina - $u$ ovom se slučaju može ustvrditi da su pristupnici sigurni u izgovor riječi, no imaju poteškoća $\mathrm{s}$ načinom njezina zapisivanja pa posežu za francuskim pravopisnim pravilima.

a) Prijenos francuske grafije

... kad čitam nešto kao filosofija (umj. filozofiju, pod utjecajem fr. grafije philosophie)

positivni (umj. pozitivni, uslijed fr. grafije positif, -ive)

Competitivna (fr. grafija compétitif, -ive, kompetitivan, natjecateljski)

Moramo ih respectirati... (fr. respecter, umj. respektirati, poštovati)

Jedna druga cultura. (fr. culture, umj. kultura)

Nemamo machinu za prat. (fr. machine, umj. mašinu, stroj za pranje, odnosno perilicu rublja)

gymnasija (prema fr. grafiji gymnase, gimnastička dvorana, umj. gimnazija) Protiv depressie (fr. dépression, umj. depresije) ${ }^{3}$

u textu (fr. texte, umj. tekstu)

b) Prijenos grafema kojim se $u$ francuskom bilježi određeni fonem

Svi vole medjede $y$ životinje... (umj. i)

Kaju da (umj. kažu da)

Za ditée koje oce (umj. dijete)

Da ye tamo med. (umj. je)

Tzilu populaciju (umj. cijelu)

B) Gramatička odstupanja na morfološkoj razini su sljedeća:

a) Nesklanjanje imena

Imam dvije brate, Olivier i Kristof. (umj. Oliviera i Kristofa)

b) Uporaba povratno-posvojne zamjenice

Zbog ove igre ljudi razvijaju njihove reflekse, kao dresiranih majmunih kad se igra... (fr. leurs, njihovi, ali i svoji, umj. svoje reflekse, kao dresirani majmuni)

To je dokaz da je lokalna stanovništva vrlo pazljiva i poštovana prema nijenovi medvjedima. (umj. prema svojim medvjedima)

c) Komparacija pridjeva

3 Riječ „depresija” ovdje se dakle javlja napisana prema francuskom dépression, sa ss. Zanimljiv je pak slučaj prijenosa francuskog pravila izgovaranja/čitanja iz jednog drugog rada s mature gdje se ista riječ javlja napisana kao deprecije, odnosno glas $s$ bilježi se kao $c$ koje se u francuskom jeziku između dva otvornika čita $s$. 
Zašto igre mogu pomoći radnicima da budu više produktivni? (fr. plus productifs, umj. produktivniji)

Imaju život više complicirano od nas. (fr. plus compliqué que nous, umj. kompliciraniji od našeg)

C) Na sintaktičkoj se razini opažuju odstupanja pod izravnim utjecajem glagolske rekcije u francuskom jeziku:

a) Glagolska rekcija

Naucili majmunu (fr. apprendre à quelqu'un, indirektni objekt, umj. naučili majmuna)

... budeš agresivan sa svjeta (fr. être agressif avec quelqu'un, umj. prema ljudima)

... da vas pomognem/ pomažem strance (fr. aider quelqu'un, direktni objekt, umj. da vam pomognem/ pomažem strancima)

... i vize smo ... odvoreni na svijet i na ljude (fr. ouvert au monde, umj. otvoreniji smo prema svijetu i ljudima)

b) Izostavljanje niječnice - $\mathrm{u}$ francuskom su u niječnim rečenicama prisutne dvije niječne jedinice, a ako se pojavi treća, jedna niječna jedinica ispada. Hrvatski sintaktički zahtijeva tzv. dvostruko nijekanje, uz niječne priloge nikad, nitko, ništa nužan je i zanijekani glagol, tj. niječnica ne. Ovdje je po uzoru na francuski u hrvatskom izostavljena niječnica ne:

... i to je loše jer ništa drugo rade osim toga (fr. c'est mauvais, parce qu'ils ne font rien (d'autre) que cela, izostavljanje negacije, umj. jer ne rade ništa drugo)

c) Prijenos konektora, veznika i glagolskih oblika iz francuskog jezika:

Ako ta ideja (igra) nije postojala, nitko to ne bih radio kao u Japanu (fr. Si cette idée/jeu n'existait pas, personne ne le ferait comme au Japon; prema francuskom jeziku gdje pogodbena rečenica za izricanje neostvarenog uvjeta u sadašnjosti zahtijeva korištenje imperfekta i kondicionala, umj. Da ta ideja (igra) ne postoji/kad ta ideja (igra) ne bi postojala, nitko to ne bi radio kao u Japanu.)

Volonteri dolazuči iz cjelog svjeta. (fr. venant du monde entier, glagolski prilog sadašnji, umj. koji dolaze)

... volonteri ... za ispričati priču o medvjedićima. (fr. pour raconter l'histoire, umj. da ispričaju priču)

d) Genitiv kojem prethodi prijedlog od

To je pozitivna strana od videoigre. (fr. du jeu vidéo, umj. videoigre)

... puno od njih su napušteni. (fr. beaucoup d'eux, umj. puno (nj)ih je napušteno) 
D) Na leksičkoj-pragmatičkoj razini opaža se velik broj prijenosnih leksičkosemantičkih odstupanja što se očituje kao uporaba doslovno prevedenih riječi ili konstrukcija gdje se leksički elementi J2 zamjenjuju elementom J1, a kod polisemičnih riječi, odabirom značenja koje se u hrvatskome jeziku u tom kontekstu ne koristi.

a) Doslovni prijevodi riječi i frazema

Nema godine za tome ali neke igre nisu za djecu... (fr. il n'y a pas d'âge pour cela, umj. za to godine nisu važne/dob nije važna)

... nemože se iskaćiti iz plajstejšona. (fr. razg. se décrocher de quelque chose, umj. ne može se odvojiti/odlijepiti od playstationa)

Donose nam ljubav koja možda i nemamo sa ljudima. (fr. apporter de l'amour, umj. pružaju, daju nam ljubav)

Okupirati se oko medvjeda. (fr. s'occuper de, umj. baviti se medvjedima)

Meni je ovo iskustvo puno voljela. (fr. j'ai beaucoup aimé cette expérience, umj. jako mi se svidjelo/sviđalo to iskustvo)

Oni su dosta puno, oko tisuću. (fr. ils sont beaucoup, umj. ima ih puno, brojni su)

Mogo bi da dožem sama za dva mjeseca. (fr. pour deux mois, iz konteksta proizlazi: na dva mjeseca)

Ako vlasnik nije eksperimentalan... (fr. expérimenté, umj. iskusan)

Treba se brinuti o njemu na svaki trenutak. (fr. à chaque instant, umj. svaki trenutak, stalno)

Kad ljudi moraju uzeti avion... (fr. prendre l'avion, umj. putovati avionom) Meni je ovo iskustvo dalo ukus za putovanje. (fr. donner le goût du voyage, umj. pobuditi strast za putovanjima)

U 2002. godine osnovano je utočište za medvjede... (fr. en 2002, umj. 2002. godine)

a) Odabir značenja kod višeznačnica

U taj smjer videoigre imaju positivan impak na cjelu firmu. (fr. sens, smjer, ali i smisao, umj. u tom smislu)

... tako da ako se svi dobro ćujemo, onda bilo dobar i mir svijet. (fr. s'entendre, čuti se, ali i razumjeti se, umj. da se svi dobro razumijemo)

Lokalno stanovništvo pokazuje njegu prema ovim medvjedićima. (fr. soin, njega, ali i briga, umj. brine o)

Kućni ljubimci su skupi za održavanje. (umj. fr. entretien, održavanje, ali i uzdržavanje)

... preživjeti od rastavu s majke... (fr. séparation, rastava, ali i odvajanje, umj. preživjeti odvajanje od majke)

Sve zavisi od toga kako je životinja uzgojena. Ako nije naučila neke važne stvari, pas će ... da se ponaša kako hoće. (fr. élever, uzgojiti, ali i odgojiti, umj. odgojena) 
... teknologija tko možeju biti dobar ali zao za ljudi. (fr. mauvais, zao, ali i loš, umj. dobre i loše za ljude)

Uvijek moraju nekoga pitati da im sačuva kućnog ljubimca. (fr. demander, pitati, ali i zamoliti, tražiti; garder, sačuvati, ali i čuvati, pričuvati, umj. moraju zamoliti nekoga da im (pri)čuva kućnog ljubimca)

\section{IZVORNA ODSTUPANJA U PISANIM RADOVIMA S DRŽAVNE MATURE U REPUBLICI FRANCUSKOJ}

Kako „,[n]asljedni govornici u inojezične učionice sa sobom donose znanje o hrvatskoj kulturi, a nerijetko i poznavanje hrvatskih nestandardnih idioma [...]" (Cvikić, Jelaska, Knajet Šimić 2010: 124), u njihovu se slučaju često može govoriti i o izvornim odstupanjima. Pretpostavka kojom se u ovom radu vodimo jest da su u promatranoj skupini ispitanika oni hrvatski jezik usvajali bilo kao materinski jezik, u krugu obitelji, bilo nekom drugom vrstom informalnog učenja, te otuda u njihovu jeziku prisutnost nestandardnih idioma. Izvorna odstupanja također se javljaju na različitim razinama.

A) Na pravopisno-fonološkoj razini očituje se kao:

a) pravopisno razvojno odstupanje u pisanju glasova č i ć, dž i đ: Moj rodžak (umj. rođak)

Nadže se (umj. nađe se)

U tekstu možemo čitati rećenicu... (umj. rečenicu...)

osječaju se (umj. osjećaju)

b) pravopisno razvojno odstupanje u bilježenju ostvaraja jata:

Smješne (umj. smiješne)

Pobjediti (umj. pobijediti)

Uvjek (umj. uvijek)

Igre mogu promjeniti svijet. (umj. promijeniti)

Ljep (umj. lijep)

c) Ispuštanje pojedinih glasova, odnosno izostanak bilježenja pojedinih slova, što odgovara izgovoru pojedinih riječi u razgovornom stilu.

Svako može (umj. svatko može)

ko zna (umj. tko zna)

Sa gejmifikacijom oče (umj. gejmifikacijom hoće...)

Može mu se reć (umj. reći)

Nekoliko dana živit s njima (umj. živjeti)

... isto kai i čovjek. (umj. kao i čovjek)

d) Sastavljeno pisanje niječnica

Nemogu (umj. ne mogu) 
Nebi (umj. ne bi)

e) Odvojeno pisanje složenica

Voziti pre brzo (umj. prebrzo)

pre agresivne (umj. preagresivne)

pre negativno (umj. prenegativno)

Kad mislimo o poslu nikad ne mislimo o igrama $i$ ako obadvoje mogu biti povezani... (umj. iako)

Po gotovo (umj. pogotovo)

B) Odstupanja na morfološkoj razini također odgovaraju bilježenju idioma iz razgovornog stila ili dijalekta.

a) $\operatorname{Rod}$

novo auto (umj. novi auto)

b) Sklonidba

... da vas vaš vjerni prijatelj čeka kući. (umj. kod kuće)

c) Konjugacija glagola

Naucia (naučija, umj. naučio)

Vidla sam puno dečke igrati (umj. vidjela sam)

Najviše sam igrao kad sam mali bijo. (umj. Najviše sam igrao kad sam bio mali.)

Samo sam s njim pričo. (umj. pričao)

Svi su tjeli otič... (umj. htjeli otići)

Kad sam bija mali uvik sam gleda televiziju. (umj. Kad sam bio mali uvijek sam gledao televiziju)

Uvik sam tijo vidit kako živu... (umj. Uvijek sam htio vidjeti kako žive...)

C) Na leksičkoj razini dolazi do odabira oblika koji odstupaju od propisane jezične norme, kao i registra neprimjerenog situaciji, odnosno stilski neprikladnih jezičnih oblika i izraza koji ne odgovaraju danom surječju.

a) Leksička odstupanja

Kada negdje idemo, uvijek možemo... (umj. nekamo)

Sad, pošto imam osamnaest godina i nema više vremena za videoigre, kužim da je to bilo negativno za mene. (umj. shvaćam)

... vrjeme u busu ... (umj. u autobusu)

Možda ne znaju šta se sve dešava. (umj. što se sve događa)

Manje naroda igra pošto imamo internet, Facebooka, Twitter. (umj. manje ljudi, budući da)

Trošenje para (umj. novca)

U parku ili bašti (umj. vrtu)

Volim otu životinju. (umj. tu) 
Provat ću nagovarat... (umj. probat ću)

D) Odstupanja su prisutna i na sintaktičkoj razini:

a) Instrumental s prijedlogom $s a$ umjesto $s$

... sa njima je lahko ... (umj. s njima)

$S a$ drugim vozačima, $s a$ prijateljima, $s a$ videoigrama (umj. s)

b) Da+prezent umjesto infinitiva

... imaju mogućnost da vide njihovim očima male i odrasle medvjede. (umj. vidjeti)

... nema šanse, moram još puno da učim! (umj. učiti)

... željeo sam da postanem veterinar. (umj. postati)

\section{VIŠESTRUKA ODSTUPANJA}

Posebno istaknimo i ovdje ono što je u ovome radu bilo očigledno iz navedenih primjera - da su odstupanja izuzetno često višestruka, te da dani primjeri zapravo mogu dobro ilustrirati i neka druga odstupanja izvan navedene vrste i razine. Uslijed višestrukosti dakako da ponekad dolazi i do poteškoća u točnijem klasificiranju odstupanja, kao u sljedećim primjerima:

Objasnaje (umj. objašnjava)

Žnači svako (umj. znači svatko)

... to što niko to ne interesuje. (umj. zato što to nikoga ne zanima)

Bolje ne ko prije. (umj. nego prije)

Napomenimo da je u nekim slučajevima posebice teško jednoznačno razlučiti radi li se o primjerice negativnom transferu iz prvog jezika ili pak o izvornom odstupanju. ${ }^{4}$ Navodimo nekoliko takvih primjera:

a) Uporaba povratno-posvojne zamjenice

Sa mojim iskustvom vidim da se danas... (fr. avec mon expérience, je vois qu'aujourd'hui; umj. Sa svojim iskustvom vidim da se danas...)

b) Glagolska rekcija

... ne smatraju medvjede kao obične životinje. (fr. considérer comme, umj. ne smatraju običnim životinjama)

c) Sintaksa

4 Naime, iako se odstupanja u određenim slučajevima mogu doimati izvornima, kod neizvornih je govornika ipak veća vjerojatnost da je u pitanju prijenosno odstupanje, vidi Gulešić-Machata, Udier 2008: 24. 
Svi budu zajedno i igraju bez da misle na problemi i na ničemu. (fr. Ils sont tous ensemble et ils jouent sans penser aux problemes et à rien d'autre.; sans+infinitiv, umj. Svi budu zajedno i igraju se ne misleći na probleme ni na što drugo.)

Na kraju, recimo još i da su neka odstupanja koja se javljaju u pisanim radovima lako prepoznatljiva te da se iz njih bez većih napora može odgonetnuti ciljani oblik. Druga odstupanja pak mogu uzrokovati komunikacijske nesporazume i dovesti do u potpunosi nerazumljivih rečenica, poput primjerice ove: „Developeri bi željeli iskoristiti video igre u politiku s državama kao Antiwargame Program, zdravlje, multinacionalne industrije kao McDonald's ili Nissan s medijama, marketing i poduzetništva ili još Microsoft što klasificira i nagrađuje zaposlenike."

\section{ZAKLJUČAK}

$\mathrm{Na}$ korpusu pisanih radova iz hrvatskog jezika kao izbornog predmeta nastalih u okviru državne mature u Republici Francuskoj 2016. i 2017. godine identificirana su i raščlanjena učestala pravopisna, gramatička, te leksička i sintaktička odstupanja koja se u tim radovima pojavljuju. Raščlamba odstupanja potvrđuje polazišnu pretpostavku o prisutnosti neizvornih, razvojnih i prijelaznih odstupanja, ali i onih izvornih, te se pokazuje kako su odstupanja vrlo često višestruka. Supostojanje većeg broja neizvornih odstupanja, ali $i$ onih karakterističnih za izvorne govornike hrvatskog jezika upućuje na to da su pristupnici hrvatski jezik većim dijelom usvajali, a ne sustavno učili, te se može pretpostaviti da je jedan od razloga za pojavu odstupanja nepostojanje institucionalnog poučavanja hrvatskog jezika u njihovim gradovima/regijama.

Hrvatske dopunske škole u Francuskoj djeluju u Parizu, u okolici Pariza (Nanterre, Beauvais), Lyonu, Nici, Annecyju, Chambéryju i Lilleu, dakle pokrivaju određeni broj akademija, a od školske godine 2016./17. u njima se počela održavati nastava u svrhu pripreme maturanata za ispit iz hrvatskog jezika. Nadalje, u francuskim je osnovnim i srednjim školama, zahvaljujući bilateralnim sporazumima između Republike Hrvatske i Francuske, unatrag nekoliko godina počela provedba programa poučavanja jezika i kulture porijekla (« enseignement de langue et de culture d'origine », ELCO), u trajanju od 1,30 minuta tjedno. Nadamo se stoga da bi rezultati ove raščlambe mogli doprinijeti postavljanju smjernica za nastavu hrvatskog jezika u Francuskoj, kako u hrvatskim dopunskim školama tako i unutar programa ELCO, odnosno na sveučilišnoj razini, gdje otprilike petinu studenata

\footnotetext{
${ }^{5}$ Riječ je o odgovoru na pitanje 1.2. iz ispita za školsku godinu 2015./16.: „U koju su svrhu nezavisni developeri željeli iskoristiti videoigre?"
} 
koji studiraju hrvatski jezik ${ }^{6}$ predstavljaju upravo studenti kojima je hrvatski nasljedni, odnosno predački jezik.

\section{LITERATURA}

Alujević Jukić, M., Brešan, T. (2010). "Prijenosne pogreške kod talijanskih izvornih govornika tijekom pisane produkcije na hrvatskom kao stranom jeziku“, Croatian studies Review 6: 242-252.

Bulletin officiel de l'Education nationale. Pristupljeno 25.4.2018. http://www.education.gouv.fr/pid285/bulletin_officiel.html?cid_bo=109192

Cvikić, L., Jelaska, Z., Knajet Šimić, L. (2010). "Nasljedni govornici i njihova motivacija za učenje hrvatskog jezika“, Croatian studies Review 6: 113127.

Fredet, F., Laurian A.-M. (2006). “Analyse interférentielle et typologie des erreurs dans l'apprentissage d'une LVE : application à l'apprentissage du roumain par des francophones “, in Linguistique contrastive, linguistique appliquée, sociolinguistique: hommage à Etienne Pietri, Peter Lang : 105-124.

Gulešić-Machata, M.,Udier, S. L. (2008) "Izvorna odstupanja u hrvatskome kao inojezičnome", Lahor 5: 19-33.

Jelaska, Z. (2014) "Vrste nasljednih govornika", Lahor 17: 83-105.

Jelaska, Z. i sur. (2005) Hrvatski kao drugi $i$ strani jezik. Zagreb: Hrvatska sveučilišna naklada.

Macan, Ž., Kolaković, Z. (2008) "Prijenosna odstupanja govornika njemačkoga u ovladavanju hrvatskim jezikom“, Lahor 5: 34-52.

Ministère de l'Enseignement supérieur, de la Recherche et de l'Innovation : Le baccalauréat et les bacheliers. Pristupljeno 24.4.2018. https://publication.enseignementsup-recherche.gouv.fr/eesr/10/EESR10_ ES_07- le_baccalaureat_et_les_bacheliers.php

Sörés, A. (2008) Typologie et linguistique contrastive. Théories et applications dans la comparaison des langues. Bern, Berlin, Bruxelles, Frankfurt am Main, New York, Oxford, Wien: Peter Lang.

\footnotetext{
6 Prema vlastitim podatcima sakupljenima tijekom višegodišnjeg iskustva u nastavi hrvatskog jezika na sveučilišnoj razini u Republici Francuskoj.
} 
Iva J. Šarić

National institute of oriental languages and civilizations (INALCO, Paris)

\title{
CROATIAN HERITAGE SPEAKERS ERRORS IN FRENCH LANGUAGE ENVIRONMENT
}

\begin{abstract}
Summary
A more systematic examination of the difficulties encountered by heritage speakers of the Croatian language whose first language is French has not been done so far. This paper will therefore identify, record, analyze and describe, using the concept of error, the most common difficulties that occur in a corpus of written exams on the Croatian language at the baccalaureate, the State High School Exit Exam in the Republic of France. The data was collected from 70 baccalaureate exams from 12 different academies in 2016, and 86 from 17 academies in 2017. The errors in those exams continually appeared at several levels, so their phonological and orthographic level, grammatical level, lexical and semantic level could be differentiated. We also noticed that the errors were very frequently multiple, which makes them difficult to categorize. The analysis of errors in this case consequently confirmed the initial hypothesis of the presence of non-native, developmental and transfer errors, but also of the native ones. The results of this analysis could contribute to the establishment of guidelines for the teaching of the Croatian language in France, both in the Croatian supplementary schools and in the ELCO program (" enseignement de langue et de culture d'origine "), as well at the universities, where approximately one fifth of students of the Croatian language are speakers to whom Croatian is native, heritage or ancestral, but not the first language.
\end{abstract}

Key words: Croatian language, French language environment, native errors, non-native errors.

Primljeno: 30. 4. 2018.

Prihvaćeno: 27. 7. 2018. 